Research Article

\title{
An Analytical Procedure to Predict Transverse Vibration Response of Jack-Up Riser under the Random Wave Load
}

\author{
Fengde Wang $\mathbb{D},{ }^{1}$ Wensheng Xiao, ${ }^{2}$ Yanan Yao, ${ }^{1}$ Qi Liu, ${ }^{2}$ and Changjiang $\mathrm{Li}^{2}$ \\ ${ }^{1}$ College of Mechanical and Electronic Engineering, Shandong University of Science and Technology, Qingdao, \\ Shandong 266590, China \\ ${ }^{2}$ College of Mechanical and Electronic Engineering, China University of Petroleum (East China), Qingdao, \\ Shandong 266580, China \\ Correspondence should be addressed to Fengde Wang; wangfengde999@sdust.edu.cn
}

Received 4 September 2019; Revised 7 May 2020; Accepted 13 May 2020; Published 28 June 2020

Academic Editor: Marco Lepidi

Copyright ( $) 2020$ Fengde Wang et al. This is an open access article distributed under the Creative Commons Attribution License, which permits unrestricted use, distribution, and reproduction in any medium, provided the original work is properly cited.

\begin{abstract}
Marine riser is a key equipment in offshore drilling operation, and failure of the riser can lead to drilling moratorium; in severe cases, it may cause oil and gas leaks. In this paper, the time-dependent boundary conditions of the riser and the randomness of wave load are considered to improve the calculation efficiency and accuracy of the dynamic response of the jack-up riser. Based on the Euler-Bernoulli beam theory, an analytical method to determine the response of the jack-up riser subjected to the random wave load was established by the Mindlin-Goodman method in the frequency domain, and an experiment was carried out to verify it. The research shows that transverse dynamic response is the main component of the transverse response of the riser, and the method proposed is feasible to calculate the transverse response of the riser.
\end{abstract}

\section{Introduction}

In this study, the jack-up riser is taken as the research object. As the main equipment of offshore oil exploration and development, the jack-up platform plays a leading role in the continental shelf waters. Jack-up platform which can decrease the lateral rigidity of the platform is designed to adapt to the growth of oil and gas demand in deeper water. Under the random environment loads, random dynamic response is produced by the platform. Although the marine riser is a key equipment in offshore drilling, it is a weak component. As the working depth of the platform increases, the dynamic response of the riser becomes more and more complicated, which may lead to operational accidents, cause huge economic losses, and even threaten the lives of operators and the marine environment. Therefore, it is necessary to study the dynamic response characteristics of the jack-up riser. In the sea area with the depth of $100-200 \mathrm{~m}$, subsea blowout preventers (BOP) are used to drill well (Figure 1). The jackup riser can be modelled as an Euler beam because of its large slenderness ratio, the top tensioning system creates axial tension force on the riser, and the lateral vibration of the platform can be treated as the time-dependent boundary conditions of the riser. Therefore, the jack-up riser can be treated as an axial-loaded Euler beam with time-dependent boundary conditions.

For the transverse vibration of the marine riser, some scholars have studied the natural vibration characteristics and forced vibration response of the riser. Ignoring the variable tension force, Clauss et al. [1] and Nayfeh et al. [2] investigated the natural vibration characteristics of the marine pipes and beams. Based on the work by Nayfeh et al., Sinir [3] investigated the pseudo-nonlinear dynamic characteristics of buckled pipes by considering the effect of internal velocity. Montoya-Hernández et al. [4] developed a numerical algorithm to evaluate the natural frequency of risers under an internal multiphase flow. Klaycham et al. [5] derived the motion equation of a large-displacement deepwater riser based on the Hamilton variational principle and studied the nonlinear-free vibration characteristics of the marine riser. By the Galerkin method, Zhou et al. [6] conducted research on the effects of the elastic constraints 


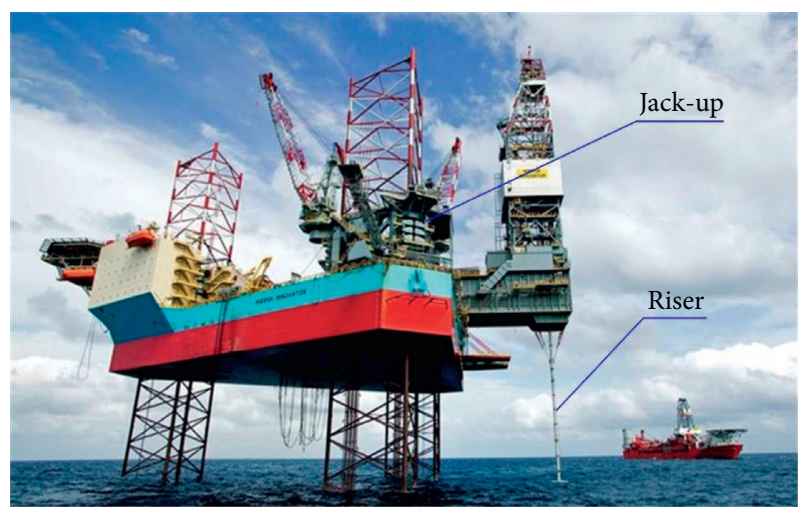

FIgURE 1: The working conditions of the jack-up platform with subsea BOP.

simulating damaged and undamaged boundaries on the natural frequencies and shapes of marine risers with a variable axial tension. Alfosail et al. [7] studied natural frequencies and mode shapes of the linear vibrations of inclined risers and proposed a numerical state-space approach to examine the natural frequencies and critical buckling limits of the marine riser [8]. Alfosail and Younis also carried out research on the two-to-one internal resonance [9] and three-to-one internal resonance of an inclined marine riser [10]; in their research, the excitation is formulated by the harmonic functions and the boundary conditions were treated as constants. Franzini and Mazzilli [11] studied the lateral motion of a slender and immersed rod subjected to harmonic and axial top motion with the reduced-order model (ROM). The dynamic response of marine risers under the harmonic excitation was also studied by Yin et al. [12]. According to the finite-difference approximation method, Wang et al. [13] put forward an idea of computing the dynamic response of risers under returning working conditions. Considering the interaction of the internal and external fluids on the marine riser, Wang et al. [14] studied lateral vibration characteristics of the riser. Reduced-order models were proposed by Vernizzi et al. [15] to investigate the parametric excitation of a vertical rod. Mao et al. [16] established a dynamic model to investigate the mechanical characteristics of a drilling riser and studied the offset of the platform as a series of determined values. For the nonlinear model, Lei et al. [17] studied the response of a deep-water riser to the platform motion, in which the motion of the platform was also treated as deterministic. Based on the Euler-Bernoulli theory, Liu et al. [18] and Zhao et al. [19] conducted research on the stabilization scheme for the flexible marine riser system, and the axial force is regarded as a constant. According to the linear wave theory, Fan et al. [20] and Wu et al. [21] investigated the vibration characteristics of the drilling riser. Do [22] proposed a constructive design of boundary controllers to stabilize lateral motion of flexible marine risers under random loads. The well posedness of the boundary conditions at the top end of the riser was studied by Guo et al. [23] with the assumption of constant axial force; and a three-dimensional simulation of the curved riser was fulfilled by Zhu et al. [24] without considering the randomness of loads. Tang et al. [25] discussed the effects of tension ratio and platform deflection on the lateral displacement, bending moment, and the stress of the drilling riser. Recently, the penalty method was applied by Klaycham et al. [26] to investigate the nonlinear response of the marine riser.

The above literature review presents that most scholars used the numerical methods to investigate the lateral vibration response of marine risers. In their research, the average axial force and harmonic functions are used to establish the mathematical model of risers, and the quasistatic method is mainly used to solve the lateral vibration response of risers. However, neglecting the randomness of load and boundary conditions will reduce the calculation accuracy of the vibration response. Based on the current research achievements, the average axial force is also applied in this paper to establish the mathematical model of a riser; but we consider the time-dependent boundary conditions of the riser and the randomness of the wave load in this paper. We propose an analytical method to determine the random lateral vibration response by the Mindlin-Goodman method. The research results can further improve the random vibration theory of beams; in terms of engineering application, this method can provide technical support to evaluate whether a special sea area and its sea conditions are available for the jack-up, can adjust the installation sequence of the riser, and improve the service life of the marine riser system. The rest of this paper is organized as follows: an analytical procedure and an experiment are elaborated in Section 2 . Then, a case study is presented in section 3. Finally, several conclusions are summarized in Section 4.

\section{Analysis}

2.1. Random Vibration Response of Jack-Up. The motion of a jack-up is treated as the time-dependent boundary condition of the riser in this research, thus it should be studied first. Figure 2 shows the sketch map of the jack-up drilling system. According to the requirements of the China classification society, the jack-up platform is modelled as a single degree of the freedom system, and the motion of the platform can be formulated by the following equation:

$$
m_{e} \ddot{u}(t)+c_{e} \dot{u}(t)+k_{e} u(t)=p(t),
$$

where $u(t)$ is the lateral displacement of the platform, $m_{e}$ is the equivalent mass of the platform, $c_{e}$ is the equivalent damping of the jack-up leg, $k_{e}$ is the bending stiffness of the jack-up leg, and $p(t)$ is the random wave load.

The frequency response function of the platform is

$$
T\left(\omega_{p}\right)=\frac{1}{-m_{e} \omega_{p}^{2}+j c_{e} \omega_{p}+k_{e}},
$$

where $\omega_{p}$ is the natural frequency of the platform. In this study, the Pierson-Moskowitz spectrum $S\left(\omega_{w}\right)$ is selected to describe the wave:

$$
S\left(\omega_{w}\right)=\frac{0.78}{\omega_{w}^{5}} \exp \left(-\frac{3.11}{\omega_{w}^{4} H_{s}^{2}}\right),
$$




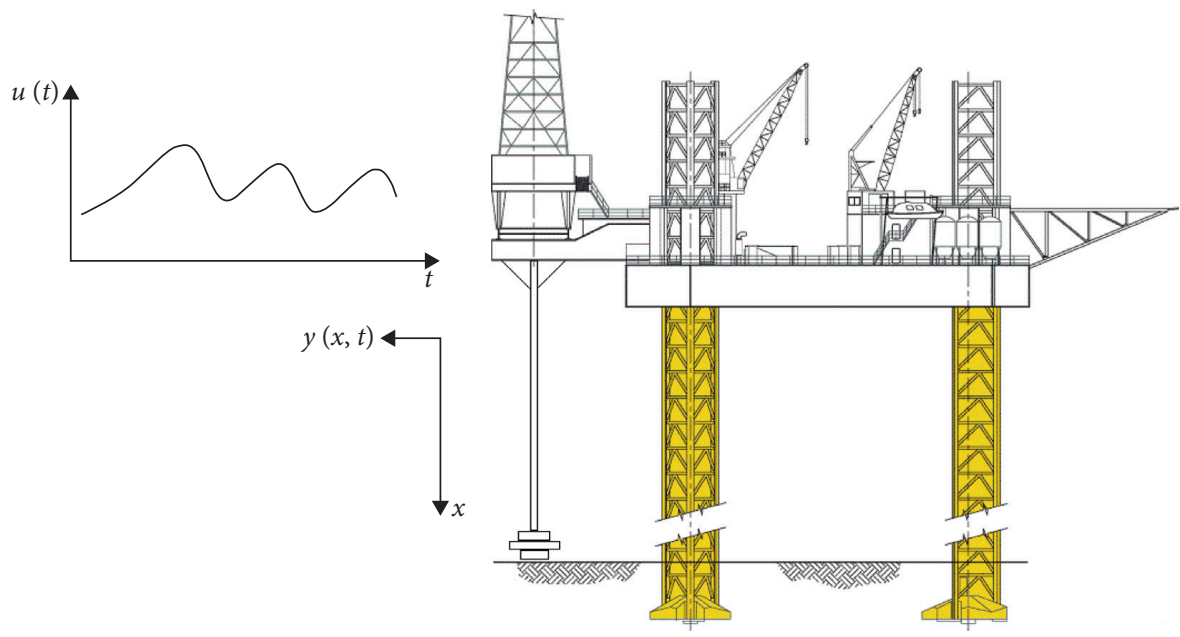

FIgURE 2: The sketch map of the jack-up drilling system.

where $H_{s}$ is the significant wave height of the wave, $\omega_{w}$ is the natural frequency of the wave, and the unit of the numerical is $\mathrm{m}^{2} / \mathrm{s}^{4}$. Based on the Morison equation and Borgman's linearization method, the total wave force spectrum of one leg of a jack-up can be obtained by the integral along the direction of the water depth, as shown in the following equation:

$$
\begin{aligned}
S_{f}\left(\omega_{w}\right)= & {\left[\frac{C_{D} \rho D_{o} \omega_{w}}{\sinh (k z)} \sqrt{\frac{2}{\pi}} \int_{0}^{z} \sigma \cosh (k h) d h\right]^{2} S\left(\omega_{w}\right) } \\
& +\left[\frac{C_{M} \rho g \pi D_{o}^{2}}{4} \tanh (k z)\right]^{2} S\left(\omega_{w}\right),
\end{aligned}
$$

where $C_{D}$ is the drag force coefficient, $C_{M}$ is the inertia force coefficient, $k$ is the wavenumber of a significant wave, $\rho$ is the density of seawater, $g$ is the gravitational acceleration, $D_{o}$ is the outer diameter of the leg, $z$ is the operating depth of the platform, and the parameter $\sigma^{2}$ is the variance of horizontal speed of the water particle, which is the function of the height $h$. Considering the linearization of the drag force is an approximate treatment, and the variance can be obtained by the following equation:

$$
\sigma \approx 0.25 H_{s} \omega_{w} \frac{\cosh (k h)}{\sinh (k z)}
$$

Substituting equation (5) into equation (4), the approximate expression of the total wave force spectrum of one leg can be derived in the following equation:

$$
\begin{aligned}
S_{f}\left(\omega_{w}\right)= & \left\{\frac{\left(C_{D} \rho D_{o} g H_{s}\right)^{2}}{32 \pi}\left[\frac{\sinh (2 k z)+2 k z}{\sinh (2 k z)}\right]^{2}\right\} S\left(\omega_{w}\right) \\
& +\left[\frac{1}{4} C_{M} \rho g \pi D_{o}^{2} \tanh (k z)\right]^{2} S\left(\omega_{w}\right) .
\end{aligned}
$$

According to the definition of power spectral density function and the relationship between autocorrelation function and power spectral density function, the total wave force spectrum of the platform $S_{p}\left(\omega_{w}\right)$ can be obtained as follows:

$$
\begin{aligned}
S_{p}\left(\omega_{w}\right)= & \left\{\frac{9\left(C_{D} \rho D_{o} g H_{s}\right)^{2}}{32 \pi}\left[\frac{\sinh (2 k z)+2 k z}{\sinh (2 k z)}\right]^{2}\right\} S\left(\omega_{w}\right) \\
& +\left[\frac{3}{4} C_{M} \rho g \pi D_{o}^{2} \tanh (k z)\right]^{2} S\left(\omega_{w}\right) .
\end{aligned}
$$

By using equations (2) and (7), the power spectral density function of the random vibration $S_{u}\left(\omega_{w}\right)$ of the platform can be obtained by the following equation:

$$
S_{u}\left(\omega_{w}\right)=\left|T\left(\omega_{p}\right)\right|^{2} S_{p}\left(\omega_{w}\right) .
$$

2.2. Random Vibration Response of Jack-Up Riser with Subsea $B O P$. When a jack-up platform uses subsea BOP to drill an exploration well, the top end of the riser is connected to the platform by a ball joint and a tension system, and the bottom end of the riser is connected to the subsea drilling system through a ball joint. In our research, several assumptions are applied as follows: (1) joints of the top end and the bottom end are modelled as a hinge; (2) the geometry characteristics and material properties of the riser are considered constant; (3) linearly varying axial force is replaced by the average axial force. Based on the above assumptions, the Euler-Bernoulli beam theory is adopted to establish the transverse motion equation of the riser as follows (without considering the internal damping of material):

$$
\mathrm{EI} \frac{\partial^{4} y(x, t)}{\partial x^{4}}-T_{m} \frac{\partial^{2} y(x, t)}{\partial x^{2}}+m \frac{\partial^{2} y(x, t)}{\partial t^{2}}+c \frac{\partial y(x, t)}{\partial t}=0
$$

where $y$ is the transverse deflection of the axis of the riser, $t$ is the time, $x$ is the coordinate measured along the beam axis, $E$ is the modulus of elasticity, $I$ is the area moment of inertia, $T_{m}$ is the average axial tensile force, $m$ is the mass per unit length, and $c$ is the damping coefficient. 
The time-dependent boundary conditions of the riser at $x=0$ and $x=l$ ( $l$ is the length of the riser) are formulated as

$$
y(0, t)=0, y(l, t)=u(t), \frac{\partial^{2} y(0, t)}{\partial x^{2}}=0, \frac{\partial^{2} y(l, t)}{\partial x^{2}}=0 .
$$

By using the Mindlin-Goodman method, the lateral deformation of the riser is decomposed into quasistatic displacement $y_{s}(x, t)$ and transverse dynamic displacement $y_{d}(x, t)$ as follows [27]:

$$
\begin{aligned}
& y(x, t)=y_{s}(x, t)+y_{d}(x, t), \\
& y_{s}(x, t)=\sum_{i=1}^{r} g_{i}(x) u_{i}(t), \\
& y_{d}(x, t)=\sum_{n=1}^{\infty} \varphi_{n}(x) q_{n}(t) .
\end{aligned}
$$

The coefficient $r$ in equation (12) is decided by the boundary conditions of the riser, and in this research, $r=1$. $\varphi_{n}(x)$ is the vibration mode function, $g_{i}(x)$ is the static influence function, and $q_{n}(t)$ is modal coordinate of $i$ th mode:

$$
g(x)=\frac{x}{l}
$$

The corresponding boundary conditions for the riser are expressed in the following equations:

$$
\begin{aligned}
& y_{s}(0, t)=0, y_{s}(l, t)=u(t), \frac{\partial^{2} y_{s}(0, t)}{\partial x^{2}}=0, \frac{\partial^{2} y_{s}(l, t)}{\partial x^{2}}=0, \\
& y_{d}(0, t)=0, y_{d}(l, t)=0, \frac{\partial^{2} y_{d}(0, t)}{\partial x^{2}}=0, \frac{\partial^{2} y_{d}(l, t)}{\partial x^{2}}=0 .
\end{aligned}
$$

Substituting equation (11) into equation (9) yields the following equation:

$$
\begin{aligned}
& \mathrm{EI} \frac{\partial^{4} y_{d}}{\partial x^{4}}-T_{m} \frac{\partial^{2} y_{d}}{\partial x^{2}}+m \frac{\partial^{2} y_{d}}{\partial t^{2}}+c \frac{\partial y_{d}}{\partial t} \\
& \quad=-E I \frac{\partial^{4} y_{s}}{\partial x^{4}}+T_{m} \frac{\partial^{2} y_{s}}{\partial x^{2}}-m \frac{\partial^{2} y_{s}}{\partial t^{2}}-c \frac{\partial y_{s}}{\partial t} .
\end{aligned}
$$

Based on equation (14), the first and second terms on the right side of equation (16) are both zero. Therefore, equation (16) is rewritten as

$$
\mathrm{EI} \frac{\partial^{4} y_{d}}{\partial x^{4}}-T_{m} \frac{\partial^{2} y_{d}}{\partial x^{2}}+m \frac{\partial^{2} y_{d}}{\partial t^{2}}+c \frac{\partial y_{d}}{\partial t}=-m \frac{\partial^{2} y_{s}}{\partial t^{2}}-c \frac{\partial y_{s}}{\partial t} .
$$

The substitution of equations (12) and (13) into equation (17) generates the following equation:

$$
\begin{aligned}
& \mathrm{EI} \sum_{n=1}^{\infty} \frac{d^{4} \varphi_{n}}{d x^{4}} q_{n}(t)-T_{m} \sum_{n=1}^{\infty} \frac{d^{2} \varphi_{n}}{d x^{2}} q_{n}(t)+m \sum_{n=1}^{\infty} \varphi_{n}(x) \ddot{q}_{n}(t) \\
& \quad+c \sum_{n=1}^{\infty} \varphi_{n}(x) \dot{q}_{n}(t)=-m g(x) \ddot{u}(t)-c g(x) \dot{u}(t) .
\end{aligned}
$$

The transverse dynamic displacement of the riser satisfies the homogeneous boundary condition, which makes the mode shape function of the riser conform to the following equation:

$$
\mathrm{EI} \frac{d^{4} \varphi_{n}(x)}{d x^{4}}-T_{m} \frac{d^{2} \varphi_{n}(x)}{d x^{2}}-m \omega_{n}^{2} \varphi_{n}(x)=0 .
$$

Substituting equation (19) into equation (20) yields the following equation:

$$
\begin{aligned}
& m \sum_{n=1}^{\infty} \varphi_{n}(x) \ddot{q}_{n}(t)+c \sum_{n=1}^{\infty} \varphi_{n}(x) \dot{q}_{n}(t)+m \omega_{n}^{2} \sum_{n=1}^{\infty} \varphi_{n}(x) q_{n}(t) \\
& \quad=-m g(x) \ddot{u}(t)-c g(x) \dot{u}(t) .
\end{aligned}
$$

By applying the orthogonality conditions, equation (20) is decoupled to the following equation:

$$
\begin{gathered}
m \ddot{q}_{n}(t)+c \dot{q}_{n}(t)+m \omega_{n}^{2} q_{n}(t)=-m \xi_{n} \ddot{u}(t)-c \xi_{n} \dot{u}(t), \\
\xi_{n}=\frac{\int_{0}^{l} g(x) \varphi_{n}(x) d x}{\int_{0}^{l} \varphi_{n}^{2}(x) d x},
\end{gathered}
$$

where $\xi_{n}$ is the weight coefficient of generalized load. According to linear theory, the frequency response function of a modal coordinate versus $u(t)$ can be obtained as follows:

$$
L_{n}(\omega)=\frac{m \xi_{n} \omega^{2}-j c \xi_{n} \omega}{m \omega_{n}^{2}-m \omega^{2}+j c \omega}
$$

where $\omega$ is the natural frequency of the riser. By equation (23), the frequency response function between the transverse dynamic displacement and $u(t)$ is generated in the following equation:

$$
L(x, \omega)=\sum_{n=1}^{\infty} \varphi_{n}(x) L_{n}(\omega), \quad(n=1,2, \ldots, \infty) .
$$

Then, the power spectral density functions of the transverse dynamic displacement can be formulated as

$$
S_{a}(x, \omega)=\sum_{n=1}^{\infty} \varphi_{n}^{2}(x)\left|L_{n}(\omega)\right|^{2} S_{u}(\omega), \quad(n=1,2, \ldots, \infty)
$$

The cross spectral density function between $u(t)$ and the transverse dynamic displacement is

$$
S_{\mathrm{as}}(x, \omega)=S_{u}(\omega) L(x, \omega) .
$$

By using the definition of autocorrelation function and the Wiener-Khinchin principle, the power spectral density 
functions of the quasistatic displacement is derived as follows:

$$
S_{s}(x, \omega)=S_{u}(\omega)[g(x)]^{2} .
$$

Based on the above analysis, the power spectral density function of the beam's transverse displacement can be obtained by the following equation:

$$
S_{y}(x, \omega)=S_{a}(x, \omega)+2 \operatorname{Re}\left[S_{a s}(x, \omega)\right]+S_{s}(x, \omega) .
$$

According to the relationship between displacement and stress, the frequency response function of bending stress response $\sigma(x, t)$ versus $u(t)$ is written as

$$
L_{\sigma}(x, \omega)=\frac{\mathrm{EI}}{W} \sum_{n=1}^{\infty} L_{n}(\omega) \frac{d^{2}}{d x^{2}} \varphi_{n}(x), \quad(n=1,2, \ldots, \infty),
$$

where $W$ is the bending modulus of the riser, and it can be calculated by equation (30). In equation (30), $D$ is the outer diameter of the riser and $d$ is the inner diameter of the riser:

$$
W=\frac{\pi\left(D^{4}-d^{4}\right)}{32 D} \text {. }
$$

On the basis of equations (25) and (29), the power spectral density functions of stress resulted from $y_{d}(x, t)$ is

$$
\begin{array}{r}
S_{a \sigma}(x, \omega)=S_{u}(\omega)\left(\frac{E I}{W}\right)^{2} \sum_{n=1}^{\infty}\left|L_{n}(\omega)\right|^{2}\left[\frac{d^{2}}{d x^{2}} \varphi_{n}(x)\right]^{2}, \\
(n=1,2, \ldots, \infty) .
\end{array}
$$

According to equations (27) and (29), the power spectral density functions of stress resulted from $y_{s}(x, t)$ is

$$
S_{s \sigma}(x, \omega)=S_{u}(\omega)\left(\frac{E I}{W}\right)^{2}\left[\frac{d^{2}}{d x^{2}} g(x)\right]^{2}, \quad(n=1,2, \ldots, \infty) .
$$

Combining equations (26) and (29), the cross power spectral density functions of the bending stress of the riser is obtained as

$$
\begin{array}{r}
S_{\mathrm{as} \sigma}(x, \omega)=S_{u}(\omega) \frac{\mathrm{EI}}{W} \sum_{n=1}^{\infty} L_{n}(\omega)\left[\frac{d^{2}}{d x^{2}} \varphi_{n}(x)\right], \\
(n=1,2, \ldots, \infty) .
\end{array}
$$

According to the summation formula of spectrum, the power spectral density function of the bending stress of the riser can be obtained by combining equations (31), (32), and (33):

$$
S_{\sigma}(x, \omega)=S_{a \sigma}(x, \omega)+2 \operatorname{Re}\left[S_{\mathrm{as} \sigma}(x, \omega)\right]+S_{s \sigma}(x, \omega) .
$$

2.3. Experimental Study. Based on the Mindlin-Goodman method, we propose an analytical method to obtain the random dynamic response of the Euler beam with axial load and time-dependent boundary conditions. Subsequently, an experiment is carried out to determine the effectiveness of our method. Overall scheme of the experiment is (a) solve the dynamic stress response of the Euler beam under the sinusoidal constant frequency excitation based on our proposed method. (b) The stress response of the beam resulted from the above sinusoidal excitation is tested by the experimental system. (c) Make a contrastive analysis of the stress response data obtained by the proposed method and the experimental test. Figure 3 shows the experiment system.

2.3.1. Harmonic Excitation. In order to better observe the experimental phenomena and collect more accurate experimental data, we constantly adjust the frequency and amplitude of the sine constant frequency excitation and then choose the following expression $E(t)$ as the excitation:

$$
E(t)=5.754 \times 10^{-3} \sin (0.314 t) .
$$

The beam in the experiment is fixed at $x=0$ and hinged at $x=l(l=0.965 \mathrm{~m})$, and the sinusoidal constant frequency excitation $E(t)$ is given to the hinge support end. The coordinate of the test point is $x=0.03 \mathrm{~m}$, and the transverse motion equation at $x=0.03 \mathrm{~m}$ of the beam is

$$
\mathrm{EI} \frac{\partial^{4} y(0.03, t)}{\partial x^{4}}+0.96 m \frac{\partial^{2} y(0.03, t)}{\partial x^{2}}+m \frac{\partial^{2} y(0.03, t)}{\partial t^{2}}=0
$$

The static influence function of the beam can be obtained by the initial parameter method, and the function of the beam's pseudostatic displacement can be derived according to equation (12):

$$
y_{s}(x, t)=E(t)\left(\frac{3 x^{2}}{2 l^{2}}-\frac{x^{3}}{2 l^{3}}\right)
$$

Then, the modal coordinate equation of the beam can be derived as

$$
\begin{aligned}
\ddot{q}_{n}(t)+\omega_{n}^{2} q_{n}(t) & =\psi_{n} E(t), \\
\psi_{n} & =\frac{\int_{0}^{l}\left[g(x)-0.96 g^{\prime \prime}(x)\right] \varphi_{n}(x) d x}{\int_{0}^{l} \varphi_{n}^{2}(x) d x},
\end{aligned}
$$

where $\psi_{n}$ is the weight coefficients of generalized load. The modal coordinates of the dynamic displacement of the beam under sinusoidal constant frequency excitation is

$$
q_{n}(t)=\frac{\psi_{n}}{\omega_{n}} \int_{0}^{t} E(\tau) \sin \omega_{n}(t-\tau) d \tau .
$$

The material of the beam is 45 carbon steel, and the diameter of the beam is $6 \mathrm{~mm}$. Since the series in equations have a fast convergence rate, the first five orders of the series are enough for the analysis. Therefore, the first five order natural frequencies of the beam and weight coefficients are calculated first, which are listed in Tables 1 and 2. Subsequently, the first five modal coordinates of the transverse dynamic displacement of the beam are calculated by equation (39). 


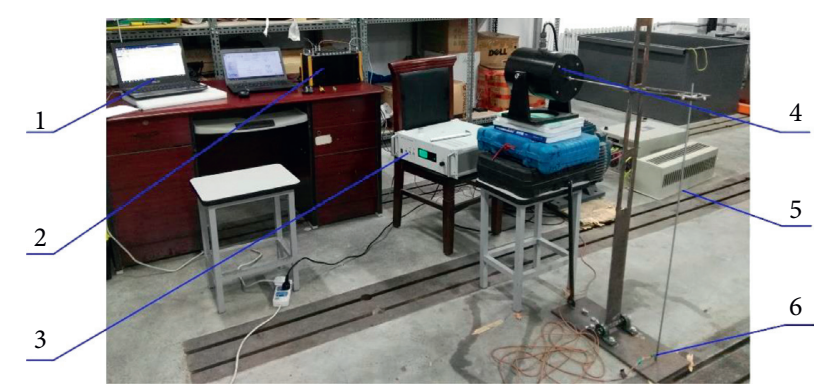

Figure 3: Diagram of the experiment system. 1, computer; 2, data analyzer; 3 , power amplifier; 4 , vibration exciter; 5 , beam; 6 , strain gage.
TABLE 1: First five order natural frequencies of the beam in the experiment.

\begin{tabular}{lccccc}
\hline$N$ & 1 & 2 & 3 & 4 & 5 \\
\hline$\omega_{n}(\mathrm{rad} / \mathrm{s})$ & 82.43 & 329.9 & 742.34 & 1319.8 & 2062.2 \\
\hline
\end{tabular}

TABLe 2: First five order load coefficients of the beam in the experiment.

\begin{tabular}{cccccc}
\hline$N$ & 1 & 2 & 3 & 4 & 5 \\
\hline$\Psi_{n}$ & -0.0033 & -0.0066 & -0.0101 & 0.0444 & 0.0547 \\
\hline
\end{tabular}

$$
q_{i}(t)=5.754 \times 10^{-3} \frac{\psi_{i}}{\omega_{i}}\left\{\begin{array}{c}
\sin \left(\omega_{i} t\right)\left[\frac{-\cos \left(0.314+\omega_{i}\right) t}{2\left(0.314+\omega_{i}\right)}-\frac{\cos \left(0.314-\omega_{i}\right) t}{2\left(0.314-\omega_{i}\right)}+\frac{1}{2\left(0.314+\omega_{i}\right)}+\frac{1}{2\left(0.314-\omega_{i}\right)}\right] \\
-\cos \left(\omega_{i} t\right)\left[\frac{\sin \left(0.314-\omega_{i}\right) t}{2\left(0.314-\omega_{i}\right)}-\frac{\sin \left(0.314+\omega_{i}\right) t}{2\left(0.314+\omega_{i}\right)}\right]
\end{array}\right\} .
$$

Based on the above analysis, the total transverse displacement of the beam in the experiment is

$$
y(x, t)=E(t)\left(\frac{3 x^{2}}{2 l^{2}}-\frac{x^{3}}{2 l^{3}}\right)+\sum_{i=1}^{5} \varphi_{i}(x) q_{i}(t) .
$$

From the relationship between displacement and stress, the stress response of the beam can be obtained as

$$
\sigma(x, t)=\frac{\mathrm{EI}}{W}\left[E(t)\left(\frac{3}{l^{2}}-\frac{3 x}{l^{3}}\right)+\sum_{i=1}^{5} q_{i}(t) \frac{d^{2}}{d x^{2}} \varphi_{i}(x)\right] .
$$

2.3.2. Experimental Results and Discussion. As the beam is cylindrical, its curved surface causes initial deformation of the strain gauge; therefore, this part of stress caused by the deformation should be subtracted from the original data. To ensure a fixation at the bottom, we installed a pin at the connection between the beam and the base, which generates bending stress; this part of stress caused by installation should be removed from the initial stress too. In Figure 4, the stress response curve obtained from theoretical method and experimental data are drawn, respectively. Due to the limitation of the experimental conditions, the foundation stiffness of the exciter and the beam is not large enough, so the extreme response amplitude of the beam is lower in the experiment.

The stress response curve obtained by experiment basically coincides with the theoretical calculation data in the main vibration response time period of the beam, which demonstrates that the proposed method is effective in solving the random response of a jack-up riser. Engineers can use our method to conduct a preliminary study of the marine riser, and if they want to accurately obtain the dynamic response of the riser at a certain position, they need to establish the motion equation at that point.

\section{Case Study}

We take a typical riser with the length of $22.86 \mathrm{~m}$ and an external diameter of $1.372 \mathrm{~m}$ as the example, and the dynamic response of the riser with subsea BOP under the random wave load is investigated in our research. The parameters of the platform are $m_{e}=6.48 \times 10^{6} \mathrm{~kg}$, $k_{e}=4.71 \times 10^{6} \mathrm{~N} / \mathrm{m}, \quad c_{e}=8.77 \times 10^{5} \mathrm{~N} \mathrm{~m} / \mathrm{s}, \quad D_{o}=3.62 \mathrm{~m}$, $E I=8.24 \times 10^{8} \mathrm{~N} \mathrm{~m}^{2}, m=461 \mathrm{~kg} / \mathrm{m}, l=110 \mathrm{~m}, T_{m}=3 \times 10^{3} \mathrm{~N}$, $H_{s}=10 \mathrm{~m}, C_{D}=2.0, C_{M}=2.0, z=100 \mathrm{~m}, \rho=1025 \mathrm{~kg} / \mathrm{m}^{3}$, and $g=9.8 \mathrm{~m} / \mathrm{s}^{2}$.

The first five order generalized load coefficients of the riser are calculated and listed in Table 3. The distribution of the stress response spectrums of the riser in the frequency domain and the spatial domain is plotted in Figures 5-7. The results show that the dynamical stress spectrum has two peak frequencies, which are the dominant frequency of the wave force spectrum and the fundamental frequency of the platform, and the total stress response spectrum is a narrow band spectrum; its dominating vibration frequency is the fundamental frequency of the platform. And, the dynamical displacement response of the jack-up riser is the main response according to the comparative analysis between Figures 5 and 7.

Based on the above research results, the mean square deviation of the random displacement response and the stress response of the riser are calculated and depicted in Figures 8 and 9. Figure 8 shows that the minimum displacement response occurs in the middle of the riser. The stress response amplitude of the riser is the largest near its top end and bottom end, and the stress response is evenly distributed in the middle area of the riser system. The dynamical response results of our study are available to evaluate whether a certain sea area meets the drilling conditions, and it can also provide technical support for adjusting the installation sequence of risers and improve the service life of the jack-up riser. 


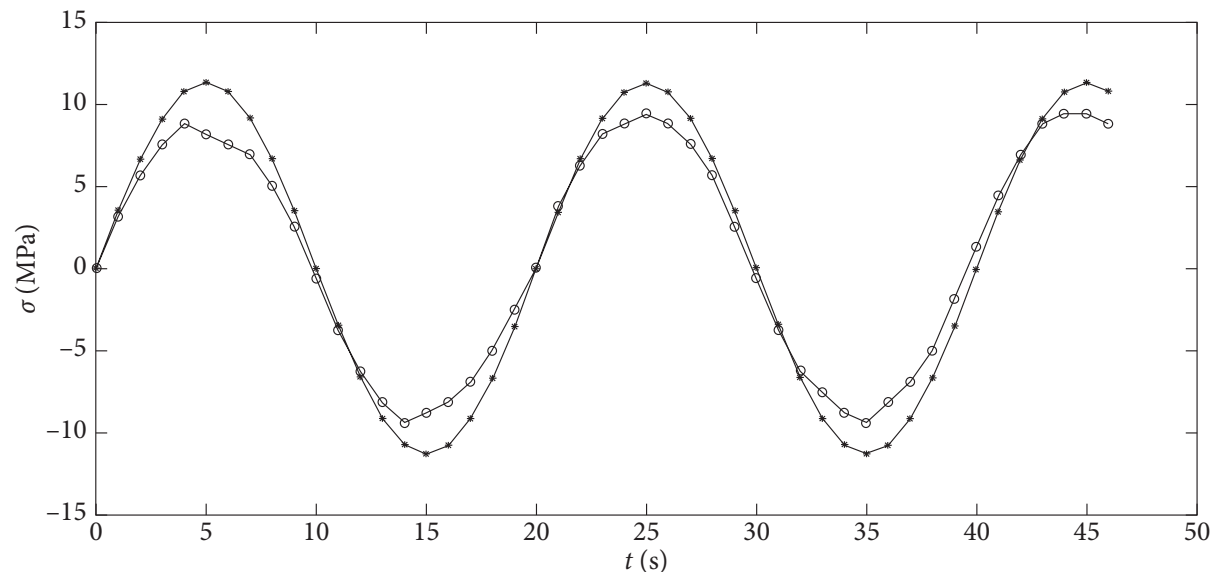

$\rightarrow$ The stress response curve obtained by the theoretical calculation

$\rightarrow$ The stress response curve obtained by the experiment

FIGURE 4: Stress response curves of the beam.

TABLE 3: Generalized load coefficients of the riser with subsea BOP.

\begin{tabular}{lccccc}
\hline$n$ & 1 & 2 & 3 & 4 & 5 \\
\hline$\xi_{n}$ & 0.6366 & -0.3183 & 0.2122 & -0.1592 & 0.1273 \\
\hline
\end{tabular}

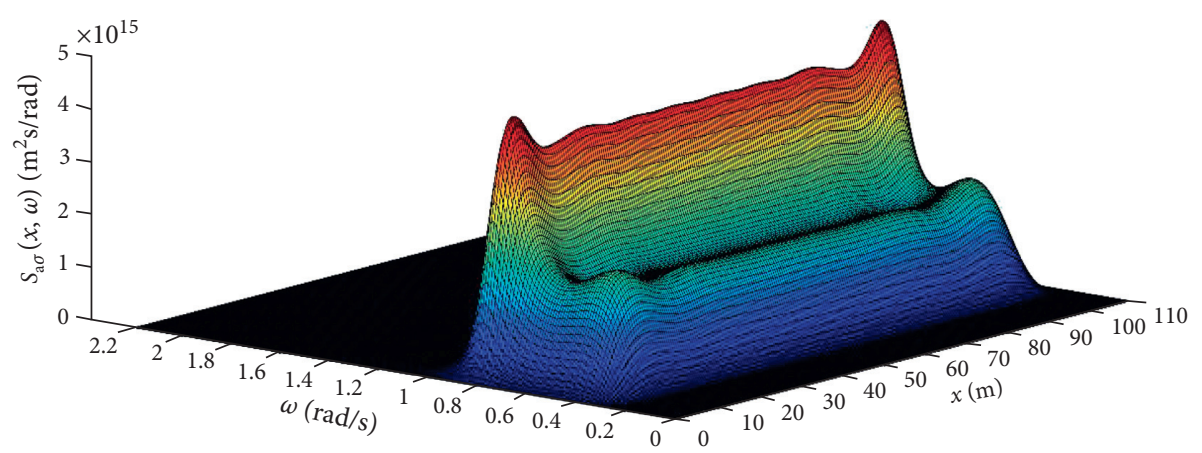

Figure 5: Stress response spectrum caused by the transverse dynamic responses $\left(H_{s}=10 \mathrm{~m}\right)$.

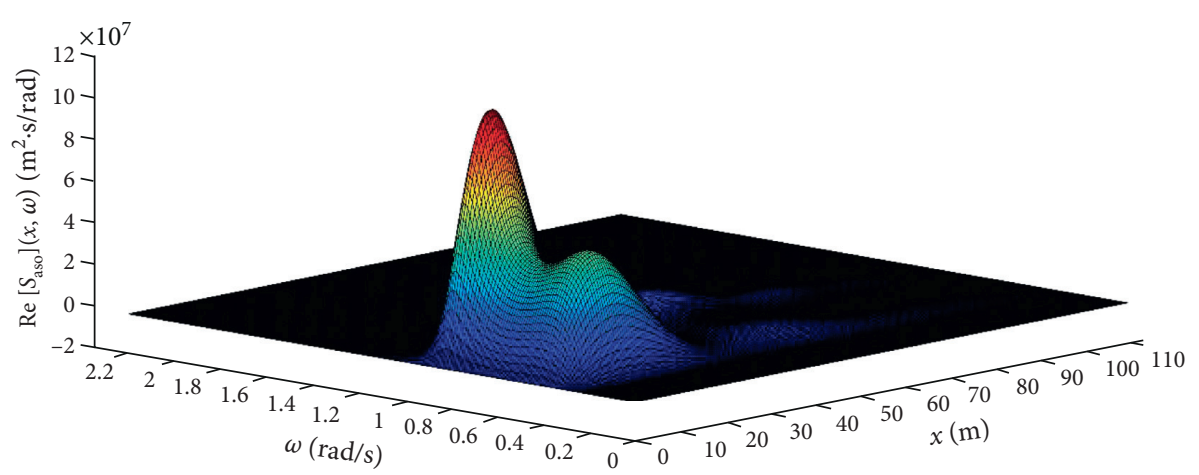

FIgURE 6: Real part of the stress cross spectrum $\left(H_{s}=10 \mathrm{~m}\right)$. 


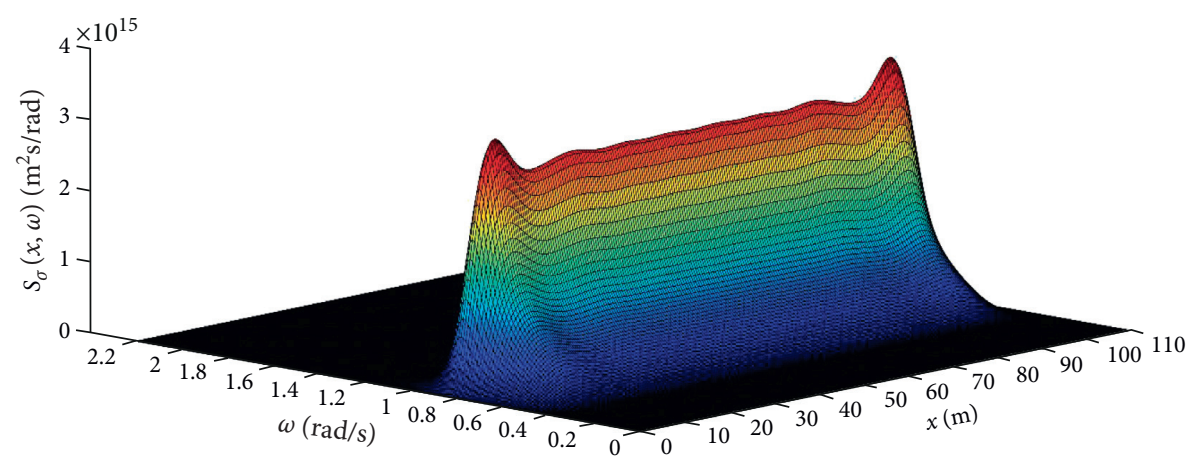

FIGURE 7: The total stress spectrum $\left(H_{s}=10 \mathrm{~m}\right)$.

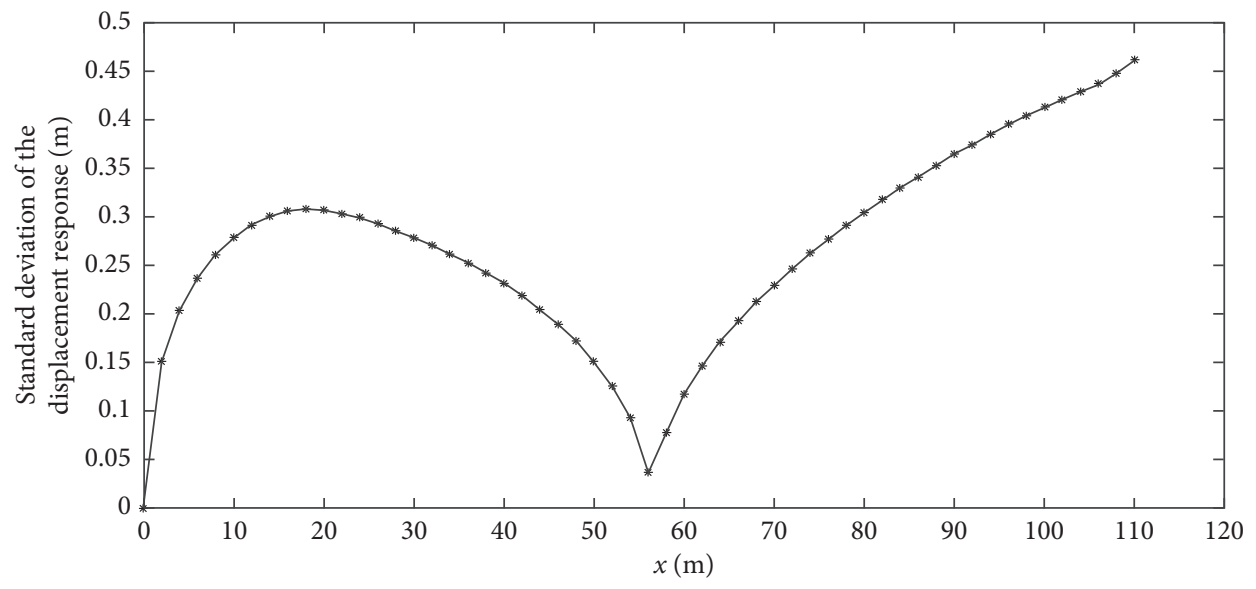

FiguRE 8: Standard deviation of the displacement response with the subsea BOP $\left(H_{s}=4.52 \mathrm{~m}\right)$.

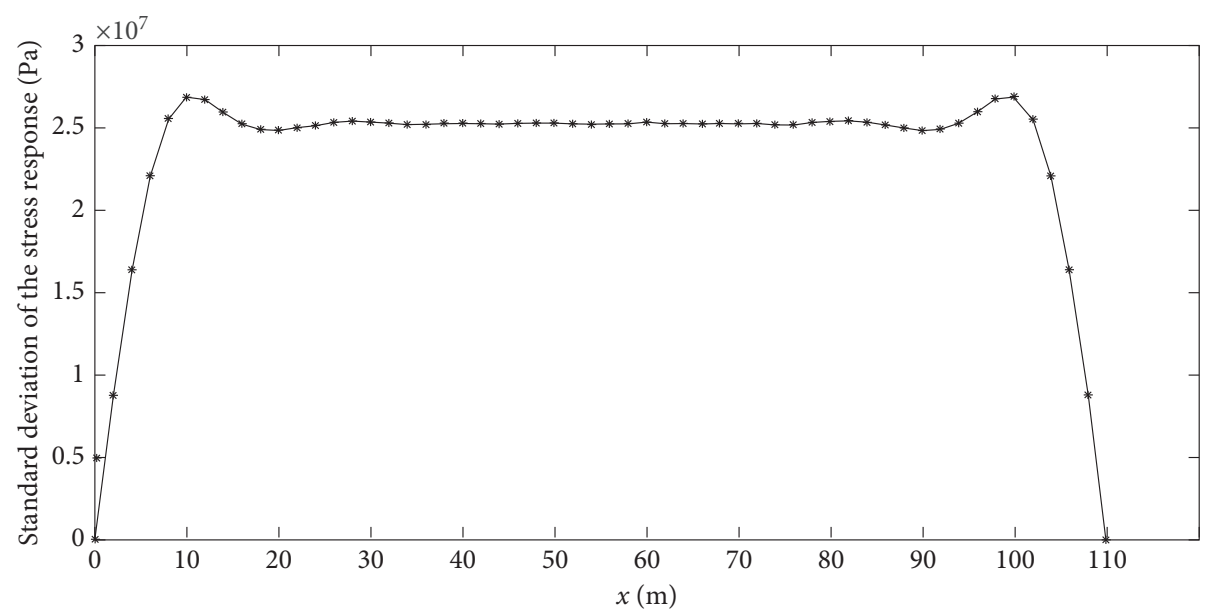

FIgURE 9: Standard deviation of the stress response with the subsea BOP $\left(H_{s}=4.52 \mathrm{~m}\right)$.

\section{Conclusions}

In this paper, a frequency domain analysis method is proposed to solve the random dynamic response of the jack-up riser with subsea BOP and time-dependent boundary conditions based on the Mindlin-Goodman method. This method can also be used to calculate the lateral response of the Euler beam with other boundary conditions. In addition, an experimental system was established and a response test experiment of the Euler beam was finished. The experimental results show that the method is effective for solving the transverse vibration response of the Euler beam. Through the case study, it is found that the lateral dynamic response of the jack-up riser is dominated by the transverse 
dynamic responses, the minimum displacement response amplitude appears in the middle of the riser system, and the maximum stress response amplitude occurs at both ends of the riser system.

\section{Conflicts of Interest}

The authors declare that there are no conflicts of interest regarding the publication of this paper.

\section{Acknowledgments}

The authors acknowledge the Ministry of Industry and Information Technology of the PR China for supporting this study through the project "Research on key technologies of integrated dismantling equipment for ultra-large offshore oilfield facilities" with the grant number 0300/ 05M1903005A.

\section{References}

[1] G. F. Clauss, H. Weede, and A. Saroukh, "Nonlinear static and dynamic analysis of marine pipelines during laying," Ship Technology, vol. 38, no. 2, pp. 76-108, 1991.

[2] A. H. Nayfeh, W. Kreider, and T. J. Anderson, "Investigation of natural frequencies and mode shapes of buckled beams," AIAA Journal, vol. 33, no. 6, pp. 1121-1126, 1995.

[3] B. G. Sinir, "Pseudo-nonlinear dynamic analysis of buckled pipes," Journal of Fluids and Structures, vol. 37, pp. 151-170, 2013.

[4] D. J. Montoya-Hernández, A. O. Vázquez-Hernández, R. Cuamatzi, and M. A. Hernandez, "Natural frequency analysis of a marine riser considering multiphase internal flow behavior," Ocean Engineering, vol. 92, pp. 103-113, 2014.

[5] K. Klaycham, C. Athisakul, and S. Chucheepsakul, "Nonlinear vibration of marine riser with large displacement," Journal of Marine Science and Technology, vol. 22, no. 2, pp. 361-375, 2017.

[6] X. Zhou, M. Duan, and J. J. Granados, "Precise integration method for natural frequencies and mode shapes of ocean risers with elastic boundary conditions," Applied Mathematical Modelling, vol. 61, pp. 709-725, 2018.

[7] F. K. Alfosail, A. H. Nayfeh, and M. I. Younis, "Natural frequencies and mode shapes of statically deformed inclined risers," International Journal of Non-linear Mechanics, vol. 94, pp. 12-19, 2017.

[8] F. K. Alfosail, A. H. Nayfeh, and M. I. Younis, "A state space approach for the eigenvalue problem of marine risers," Meccanica, vol. 53, no. 4-5, pp. 747-757, 2018.

[9] F. K. Alfosail and M. I. Younis, "Two-to-one internal resonance of an inclined marine riser under harmonic excitations," Nonlinear Dynamics, vol. 95, no. 2, pp. 1301-1321, 2019.

[10] F. K. Alfosail and M. I. Younis, "Three-to-one internal resonance of inclined marine riser," International Journal of Non-linear Mechanics, vol. 109, pp. 107-117, 2019.

[11] G. R. Franzini and C. E. N. Mazzilli, "Non-linear reducedorder model for parametric excitation analysis of an immersed vertical slender rod," International Journal of Nonlinear Mechanics, vol. 80, pp. 29-39, 2016.

[12] D. Yin, E. Passano, H. Lie et al., "Experimental and numerical study of a top tensioned riser subjected to vessel motion," Ocean Engineering, vol. 171, pp. 565-574, 2019.
[13] S.-w. Wang, X.-s. Xu, B.-h. Yao, and L. Lian, "A finite difference approximation for dynamic calculation of vertical free hanging slender risers in re-entry application," China Ocean Engineering, vol. 26, no. 4, pp. 637-652, 2012.

[14] Y. Wang, D. Gao, and J. Fang, "Study on lateral vibration analysis of marine riser in installation-via variational approach," Journal of Natural Gas Science and Engineering, vol. 22, pp. 523-529, 2015.

[15] G. J. Vernizzi, G. R. Franzini, and S. Lenci, "Reduced-order models for the analysis of a vertical rod under parametric excitation," International Journal of Mechanical Sciences, vol. 163, p. 105122, 2019.

[16] L. Mao, Q. Liu, S. Zhou, G. Wang, and Q. Fu, "Deep water drilling riser mechanical behavior analysis considering actual riser string configuration," Journal of Natural Gas Science and Engineering, vol. 33, pp. 240-254, 2016.

[17] S. Lei, X. Y. Zheng, and D. Kennedy, "Dynamic response of a deepwater riser subjected to combined axial and transverse excitation by the nonlinear coupled model," International Journal of Non-linear Mechanics, vol. 97, pp. 68-77, 2017.

[18] Y. Liu and F. Guo, "Output feedback boundary control of a flexible marine riser system," Journal of Vibration and Control, vol. 24, no. 16, pp. 3617-3630, 2017.

[19] Z. Zhao, Y. Liu, and F. Guo, "Robust output feedback stabilization for a flexible marine riser system," ISA Transactions, vol. 78, pp. 130-140, 2018.

[20] H. Fan, C. Li, Z. Wang, L. Xu, Y. Wang, and X. Feng, "Dynamic analysis of a hang-off drilling riser considering internal solitary wave and vessel motion," Journal of Natural Gas Science and Engineering, vol. 37, pp. 512-522, 2017.

[21] Z. Wu, C. Xie, G. Mei, and H. Dong, "Dynamic analysis of parametrically excited marine riser under simultaneous stochastic waves and vortex," Advances in Structural Engineering, vol. 22, no. 1, pp. 268-283, 2019.

[22] K. D. Do, "Boundary control of transverse motion of flexible marine risers under stochastic loads," Ocean Engineering, vol. 155, pp. 156-172, 2018.

[23] F. Guo, Y. Liu, Y. Wu, and F. Luo, "Observer-based backstepping boundary control for a flexible riser system," Mechanical Systems and Signal Processing, vol. 111, pp. 314-330, 2018.

[24] H.-j. Zhu and P.-Z. Lin, "Numerical simulation of the vortexinduced vibration of a curved flexible riser in shear flow," China Ocean Engineering, vol. 32, no. 3, pp. 301-311, 2018.

[25] L. Tang, Z. Huang, X. Zhu, Y. Zhou, and B. Li, "Investigation of the mechanical response of a deep-water drilling riser to ocean currents and waves," Advances in Mechanical Engineering, vol. 11, no. 1, pp. 1-11, 2019.

[26] K. Klaycham, C. Athisakul, and S. Chucheepsakul, "Nonlinear response of marine riser with large displacement excited by top-end vessel motion using penalty method," International Journal of Structural Stability and Dynamics, vol. 25, Article ID 2050052, 2020.

[27] R. W. Clough and J. Penzien, Dynamics of Structures, McGraw-Hill, New York, NY, USA, 3rd edition, 1995. 